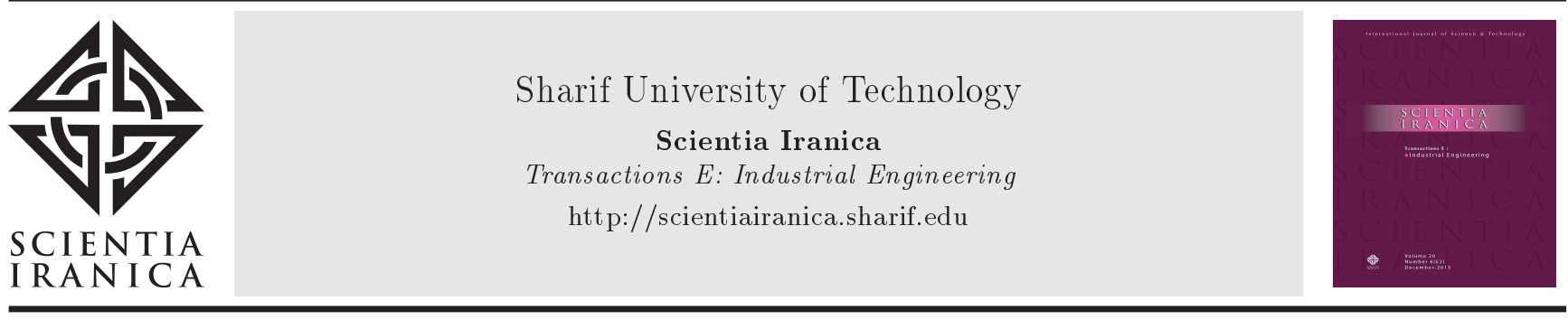

\title{
Green closed-loop supply chain network design with stochastic demand: A novel accelerated benders decomposition method
}

\author{
A.R. Kalantari Khalil Abad and S.H.R. Pasandideh* \\ Department of Industrial Engineering, Faculty of Engineering, Kharazmi University, Tehran, Iran.
}

Received 1 May 2019; received in revised form 25 August 2020; accepted 21 September 2020

KEYWORDS
Green supply chain
network design;
Uncertainty;
Two-stage stochastic
scenario-based
programming;
Emission capacity;
Accelerated Benders
decomposition
algorithm;
Pareto-optimality cut.

\section{KEYWORDS}

Two-stage stochastic

scenario-based

programming;

Emission capacity

decomposition

Pareto-optimality cut.

\begin{abstract}
Changing the structure of supply chains to move towards less polluting industries and better performance has attracted many researchers in recent studies. Design of such networks is a process associated with uncertainties and control of the uncertainties during decision-making is of particular importance. In this paper, a two-stage stochastic programming model is presented for the design of a green closed-loop supply chain network. In order to reach the environmental goals, an upper bound of emission capability that would help governments and industries to control greenhouse gas emissions was considered. During the reverse logistics of this supply chain, waste materials were returned to the forward flow by the disassembly centers. To control the uncertainty of strategic decisions, demand and the upper bound of emission capacity with three possible scenarios were considered. To solve the model, a new accelerated Benders decomposition algorithm along with Pareto-optimal-cut was used. The efficiency of the proposed algorithm was compared with the regular Benders algorithm. The effect of different numerical values of parameters and probabilities of scenarios on the total cost was also examined.
\end{abstract}

(C) 2022 Sharif University of Technology. All rights reserved.

\section{Introduction}

In the design of supply chain networks, several concepts are considered. One of these concepts is greenness. Today, with the expansion of collaboration between various components of supply chains along with the spread of globalization, increased pollution due to industrialization, and the establishment of environmental restrictions by governments, in addition to

\footnotetext{
*. Corresponding author. Tel.: +982188830891;

Fax: +982188329213

E-mail addresses: Nimakalantari1374@gmail.com (A.R.

Kalantari Khalil Abad); shr_pasandideh@khu.ac.ir (S.H.R. Pasandideh)
}

doi: $10.24200 /$ sci.2020.53412.3249 costs reduction and improvement of the quality of final product in the design of supply chains, green technology is gaining more and more attention of the researchers. According to the report of the World Commission on Development and Environment, the aim of supply chain designing is to "meet the needs of the present without compromising the ability of future generations to meet their own need" [1].

Another issue in the design of networks is the concept of open-loop and close-loop supply chains. Close-loop supply chains are often employed in order to reduce return products and waste as well as to increase efficiency. In a provided supply chain network, the return flow includes several types of materials: end of use (EOF), end of life (EOL), unused raw materials, and so on. Usually many companies neglect recycling 
of EOL materials, while new regulatory frameworks in Europe and in the United States have several aims: waste prevention, recycling, disposal options, etc. Therefore, these frameworks require supply chains to be reconstructed [2].

Last but not the least, handling the uncertainty caused by strategic decisions is another issue. In supply chains, decisions are often divided into several strategic, tactical, and operational categories based on multiplicity criteria and timing. Strategic decisions are large-scale chain-level decisions that outline the structure of the supply chain. These decisions include determining the location and capacity of the facility, how suppliers provide raw materials, and various methods of production and transportation. Tactical and operational decisions have shorter horizons and regulate the flow of products between various components of a supply chain. Strategic decisions are important for significant investments and have direct impact on other decisions. One important point is that the long time span of these decisions cause uncertainty that should be taken into account when predicting future conditions [3].

Based on these basic concepts, the aim of this research is to design a new green complex supply chain with both direct and reverse flows. It should also be noted that for the design of this Green Supply Chain (GSC), a Mixed Integer Linear Programming (MILP) model was used. This model locates appropriate candidates for a facility site discretely and establishes the flow of facilities as well. Our model also determines the transportation method between the various components of supply chain. To control the emission of greenhouse gases, an upper bound of emission capacity was used. Governments or oversight bodies determine such an upper bound. Since strategical and tactical decisions in the network design were made in two phases, the two-stage stochastic scenario-based programming approach was used for uncertainty modeling. Also, for the first time, both the demand and the upper bound of the emission capacity were modeled based on stochastic probability scenarios. To solve the problem, a new accelerated decomposition Benders algorithm was used. The proposed Benders algorithm has a much better performance than the regular Benders algorithms. Also, the non-deterministic parameters and the probabilities of occurrence of scenarios were analyzed under different circumstances.

Different sections of this study are categorized as follows: Section 2 gives an overview of the past research and the existing literature gaps. Section 3 presents goals, assumptions, application of research, and the stochastic scenario based model along with introducing the sets, parameters, and decision variables. Section 4 describes the novel accelerated Benders algorithm and finally, Section 5 presents experimental examples and sensitive analysis for the suggested algorithm.

\section{Literature review}

Many studies have been done on the design of the supply chain networks. Yang et al. [4] in their article designed a closed-loop supply chain with various production and reproduction rings. Their supply chain consisted of a producer, distributor, supplier and collector. They incorporated only the economic goals. Che et al. [5] offered a supplier selection model that considered a discount policy. In their model, they only considered the goal of maximizing supplier revenue and defects and used Particle Swarm Optimization (PSO) to solve the problem. Moncayo-Martínez and Zhang [6] presented a supply chain with the goal of reducing costs and delivery times in a multi-objective model. To solve their model, they used Pareto Ant Colony algorithm. In the design of this supply chain, like many others, environmental goals and uncertainty were not taken into consideration. However, today, the optimal supply chain performance depends on the realization of environmental aims and realistic modeling based on uncertainty in the parameters. Regarding supply chains with environmental considerations in addition to economic factors in their design, Jamshidi et al. [7] presented a multi-objective model for an openloop supply chain that in addition to minimizing transportation, maintenance, and back order costs, minimized emissions of greenhouse gases. Tognetti et al. [8] provided a model for a sustainable three-level supply chain. For the first time, their model reached sustainability goals in supply chains. Shaw et al. [9] also provided a multi-objective model for designing a sustainable open-loop supply chain and solved it using Benders algorithm. Varsei and Polyakovskiy [10] designed a sustainable wine supply chain. They used two integrated integer programming models and a real case to test the model. Devikaa et al. [11] presented an MILP model that considered financial and environmental goals in a closed-loop supply chain. Nurjanni et al. [2] presented a new modeling of the GSC network design, which perfectly met the sustainability goals and considered direct and reciprocal flows simultaneously. In their model, transportation methods between the four components of the supply chain were also determined. Among the studies that have considered uncertainty and used a fuzzy approach to modeling, Mohammed and Wang [12] presented a multi-objective model for designing a meat supply chain with the goal of minimizing the cost of transportation, the amount of $\mathrm{CO}_{2}$ emissions from transport, and the time of transfer and distribution as well as maximizing the delivery rate. They used fuzzy parameters to model uncertainty in the open-loop supply chain. Soleimani 
and Kannan [13] designed a closed-loop network of multi-layer supply chains in which sustainability goals were realized. In their model, fuzzy parameters were used to model uncertainty. They also developed an extended genetic algorithm to solve the model. Imran et al. [14] developed a model for a medical supply chain. They treated the medical and pharmaceutical complaints received by the manufacturer with uncertainty and in a fuzzy manner. Some other researchers have also used fuzzy methods in their studies [15-18]. In order to control the uncertainty, methods based on probability theory such as stochastic programming and robust optimization have also been used. Paydar et al. [19] developed a multi-objective model for a closedloop supply chain for the collection and distribution of motor oil whose aim was to maximize profits and minimize risk. They used robust stochastic programming to model uncertainty. Amin et al. [20] in their single-objective model designed a multi-product, multicycle supply chain that considered both the forward and backward flows. In their model, they considered demand and supply parameters as uncertain. Many other studies have also used stochastic programming approaches, robust optimization, and a combination of both to control uncertainty [21-25]. Regarding the studies that focus on both sustainability and uncertainty based on probability theory in the supply chain, Rezaee et al. [26] presented a two-stage stochastic model in a green open-loop supply chain. They used the carbon trading scheme in their model and treated carbon demand and price parameters with uncertainty. Pasandideh et al. [27] developed a sustainable supply chain using a nonlinear and multi-objective model that minimized the average and variance of supply chain costs. They used stochastic (probabilistic) programming to model uncertainty. Banasik et al. [28] designed a closed-loop chain that realized economic and environmental goals. They implemented the proposed model in the mushroom industry, improving a company's profits by $11 \%$ and reducing environmental impacts by $28 \%$. Heidari-Fathian and Pasandideh [29] presented an MILP model for a green blood supply chain. They treated the demand and supply of blood with uncertainty and developed the problem by using robust stochastic programming. To solve the model, they used the Lagrangian relaxation algorithm.

The novelties of the present study include the following:

- Modelling perspective: For the first time, a mathematical model is offered with all features including closed loop, greenness, determination of the transportation method with cost and environmental considerations, and incorporation of the uncertainty issue in the demand and upper bound of emission capacity for the design of a green closed-loop supply chain.

- Solution method: Our major contribution is to develop two exact decomposition methods including regular Benders and accelerated Benders decomposition algorithms with the Pareto-optimal-cut to solve a green closed-loop network design problem. Benders decomposition-based approaches have been widely used in solving a supply chain network, but this is the first time that an accelerated Benders decomposition algorithm with Pareto-optimal-cut is employed to solve the GSC network design problem with uncertainty control. To better illustrate the gaps in the previous studies, Table 1 is presented.

\section{Problem description and assumptions}

The process of supply chain network design involves the adoption of strategic and operational decisions. During this process, the aim of both locating appropriate candidates for facility sites and the flow between the facilities is cost reduction, but some factors influence this process, including the uncertainty associated with the decision-making process and environmental pollution, which has become one the most prevalent global issues. Nowadays, for this reasons, in the design of complex networks, three elements are very important in modeling: (1) reaching economic and environmental goals, (2) handling uncertainty, and (3) determining the transportation mode.

The presented novel mathematical model creates a complex network of plants, warehouses, customers, and disassembling centers as shown in Figure 1. The objectives of this GSC network include: (1) increasing the quality of output products, (2) reducing costs (production, re-production, collection, storage, and transportation costs), (3) reducing waste from EOL products, (4) reducing greenhouse gas emissions, and (5) controlling the uncertainties of strategic decisions. The model also considers several methods of transportation between the components of the supply chain (road, rail, sea, air, etc.). The transportation method is selected based on cost and greenhouse gas emissions of the model.

The flow in this closed-loop supply chain is divided into three categories: (1) direct flow of intact products from factory to customer, (2) reverse flow of EOL products passed from the customer to the disassembly centers and returned to the main path, and (3) flow of EOU product returns to the mainstream after collecting from customers and recycling. These reverse flows reduce waste.

The assumptions of the proposed model are as follows:

- The model is single-product and single-period; 
Table 1. A summary of the mathematical models in the literature and the gaps covered by this article.

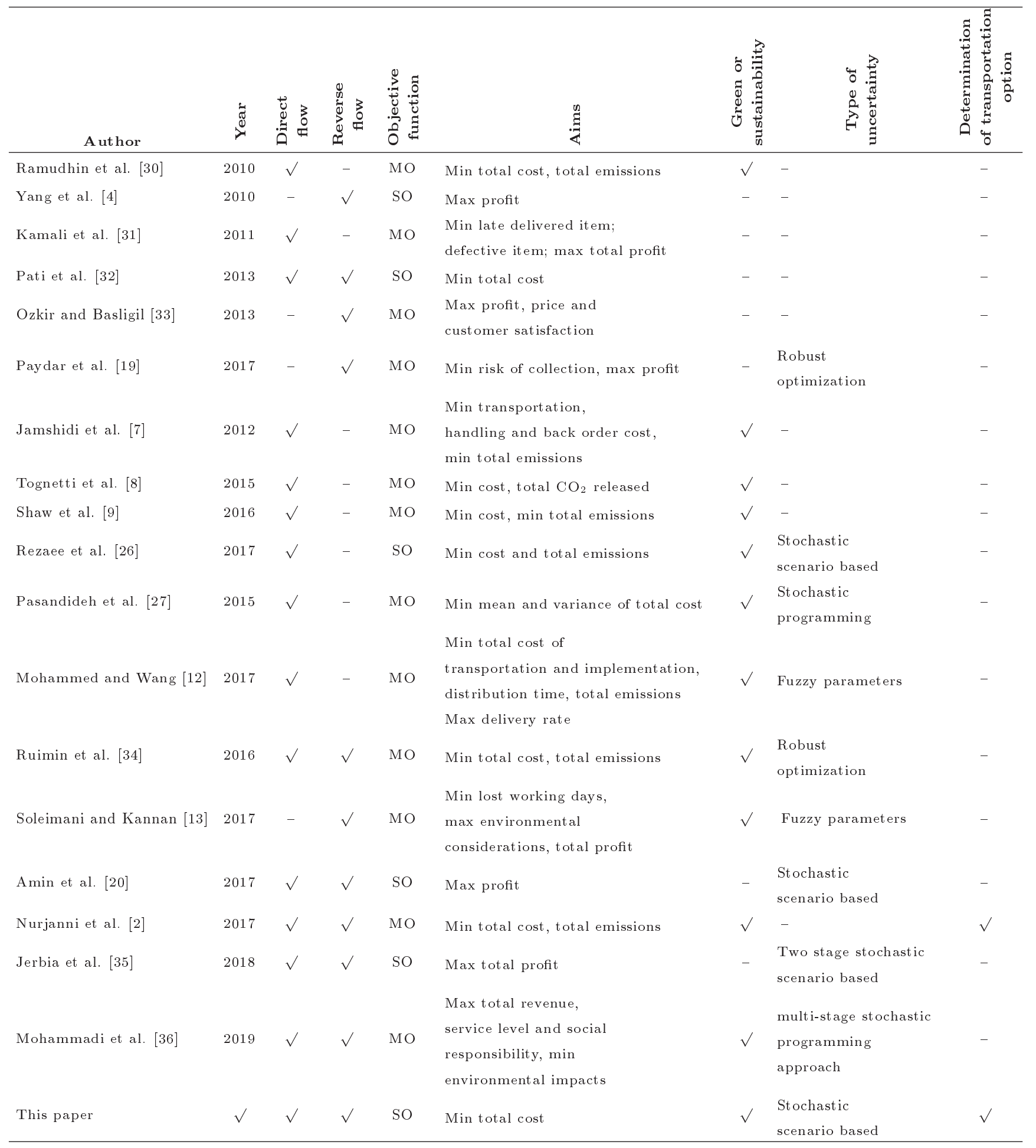

- For all greenhouse gas emissions, upper bound of emission capability is considered;

- Shortage is not allowed;

- Demand of customers and the upper bound of emission capacity are considered as uncertain parameters;
- A non-negligible percentage of customer demand is considered as the minimum quantity of disposable products. Consequently, a certain percentage of the disposable products is considered as the minimum of recyclable materials;

- A certain percentage of waste products and a per- 


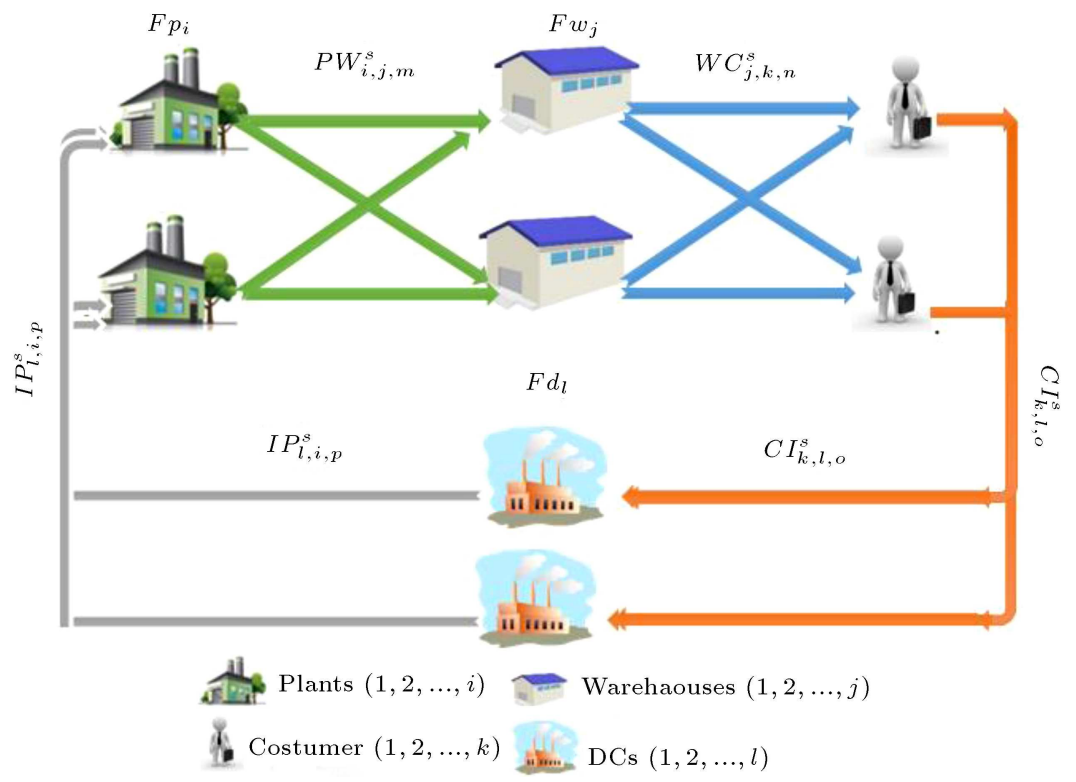

Figure 1. Linking of the flows between different sectors of the green supply chain network.

centage of reproducible products are assumed to be definite parameters;

- All costs are considered without using the conversion factor of the present value to the future value.

\subsection{Model indices}

Table 2 presents the indices of plants, warehouses, customers and disassembly centers. Indices are also defined for the transportation method from plants to warehouses, warehouses to customers, customers to disassembly centers, and disassembly centers to plants. Yet, another index is defined for possible scenarios.

\subsection{Model parameters}

Table 3 illustrates the parameters of the problem in hand. As it is known, upper bound of emission capacity $\left(c a p^{s}\right)$ and customer demand $\left(d_{k}^{s}\right)$ are based on probable scenarios for their occurrence. These two parameters are independent of each other. Therefore, the total number of probable scenarios is equal to the outcome of the multiplication of the number of scenarios for the upper bound of emission capacity by the customer demand parameter. According to the principle of the occurrence probability of independent events, the probability of these parameters is equal to the result of multiplying the probability of each one.

\subsection{Model decision variables}

Tables 4 and 5 state the decision variables of the problem. Binary variables are related to strategic decisions that are used to locate facilities in discrete locations. Continuous variables also relate to operational decisions that make flow between facilities.

\subsection{Model formulation}

In the modeling, the objective function of the problem consists of two parts: (1) strategic decisions and (2) operational decisions. In the first part, fixed costs are set for the construction of plants, warehouses, and disassembly centers. The second part of the objective function consists of two parts: (1) variable costs and (2) shipping costs. Variable costs are foreseen for

Table 2. Problem indictors.

\begin{tabular}{ll}
\hline Index & \multicolumn{1}{c}{ Description } \\
\hline$I$ & Index for plants $(i=1,2, \ldots,|I|)$ \\
$J$ & Index for warehouses $(j=1,2, \ldots,|J|)$ \\
$K$ & Index for customers $(k=1,2, \ldots,|K|)$ \\
$L$ & Index for DSs $(l=1,2, \ldots,|L|)$ \\
$M$ & Index for transportation options from plants $(m=1,2, \ldots,|M|)$ \\
$N$ & Index for transportation options from warehouses $(n=1,2, \ldots,|N|)$ \\
$O$ & Index for transportation options from customers $(o=1,2, \ldots,|O|)$ \\
$P$ & Index for transportation options from DCs $(p=1,2, \ldots,|P|)$ \\
$S$ & Index for scenarios $(s=1,2, \ldots,|S|)$ \\
\hline
\end{tabular}


Table 3. Problem parameters.

\begin{tabular}{|c|c|}
\hline Parameter & Description \\
\hline$c p_{i}$ & Fixed cost for establishing plant $i \in I$ \\
\hline$c w_{j}$ & Fixed cost for establishing warehouse $j \in J$ \\
\hline$c d_{l}$ & Fixed cost for establishing DC $l \in L$ \\
\hline$c^{\prime} p_{i}$ & Unit variable cost for producing a unit product in plant $i \in I$ \\
\hline$c^{\prime} w_{j}$ & Unit variable cost for handling a unit of product in the warehouse $j \in J$ \\
\hline$c^{\prime} c_{k}$ & Unit variable cost for collecting a unit of product to be disposed from customer $k \in K$ \\
\hline$c^{\prime} d_{l}$ & Unit variable cost for disassembling a unit of product to be disposed in DC $l \in L$ \\
\hline$c^{\prime} r_{i}$ & Unit variable cost for reproducing a unit product in plant $i \in I$ \\
\hline$c^{\prime \prime} p_{i, j, m}$ & Unit transportation cost from plant $i$ to warehouse $j$ by the transportation method $m$ \\
\hline$c^{\prime \prime} w_{j, k, n}$ & Unit transportation cost from warehouse $j$ to customer $k$ by the transportation method $n$ \\
\hline$c^{\prime \prime} c_{k, l, o}$ & Unit transportation cost for collecting unit of product from customer $k$ to $\mathrm{DC} l$ by the transportation method $o$ \\
\hline$c^{\prime \prime} d_{l, i, p}$ & Unit transportation cost from DC $l$ to plant $i$ by the transportation method $p$ \\
\hline$e p_{i}$ & Rate of released $\mathrm{CO}_{2}$ to produce one unit of product in plant $i$ \\
\hline$e w_{j}$ & Rate of released $\mathrm{CO}_{2}$ to handle and store one unit of product in warehouse $j$ \\
\hline$e d_{l}$ & Rate of released $\mathrm{CO}_{2}$ to disassemble one unit of product to be disposed in DC $l$ \\
\hline$e r_{i}$ & Rate of released $\mathrm{CO}_{2}$ to remanufacture one unit of product to be dismantled in plant $i$ \\
\hline$e^{\prime \prime} p_{m}$ & $\begin{array}{l}\mathrm{CO}_{2} \text { released by the transportation method } m \text { to forward a unit of product from factory to warehouse } \\
\text { for a unit distance }\end{array}$ \\
\hline$e^{\prime \prime} w_{n}$ & $\begin{array}{l}\mathrm{CO}_{2} \text { released by the transportation method } n \text { to forward a unit of product from warehouse to } \\
\text { customer for a unit distance }\end{array}$ \\
\hline$e^{\prime \prime} c_{o}$ & $\begin{array}{l}\mathrm{CO}_{2} \text { released by the transportation method } o \text { to collect a unit disposal from customer to DC for a } \\
\text { unit distance }\end{array}$ \\
\hline$e^{\prime \prime} d_{p}$ & $\begin{array}{l}\mathrm{CO}_{2} \text { released by the transportation method } p \text { to ship a unit of product to be dismantled from DC } \\
\text { to plant for a unit distance }\end{array}$ \\
\hline$u p_{i}$ & Maximum production capacity of plant $i$ \\
\hline$u w_{j}$ & Maximum storage and handling and processing capacities of warehouse $j$ \\
\hline$u d_{l}$ & Maximum disassembly capacity of DC $l$ \\
\hline$u r_{i}$ & Maximum reproduction capacity of plant $i$ \\
\hline$\gamma p_{i, j, m}$ & Transportation rate from pant $i$ to warehouse $j$ by the transportation method $m$ \\
\hline$\gamma w_{j, k, n}$ & Transportation rate from warehouse $j$ to customer $k$ by the transportation method $n$ \\
\hline$\gamma c_{k, l, o}$ & Transportation rate for collecting a unit of product from customer $k$ to DC $l$ by the transportation method $o$ \\
\hline$\gamma d_{l, i, p}$ & Transportation rate from $\mathrm{DC} l$ to plant $i$ by the transportation method $p$ \\
\hline$s p_{i, j}$ & Distance between plant $i$ and warehouse $j$ \\
\hline$s w_{j, k}$ & Distance between warehouse $j$ and customer $k$ \\
\hline$s c_{k, l}$ & Distance between customer $k$ and DC $l$ \\
\hline$s d_{l, i}$ & Distance between DC $l$ and plant $i$ \\
\hline$\alpha$ & Minimum percentage of units of product to be disposed to be collected from a customer \\
\hline$\alpha^{\prime}$ & Minimum percentage of units of product to be dismantled to be shipped from a DC \\
\hline$d_{k}^{s}$ & Demand of customer $k$ in scenario $s$ \\
\hline$c a p^{s}$ & $\begin{array}{l}\text { Upper bound of emission capacity of } \mathrm{CO}_{2} \text { released in scenario } s \text {, which is determined by the } \\
\text { government and regulatory bodies }\end{array}$ \\
\hline$\theta^{s}$ & Probability of scenario $s$ \\
\hline
\end{tabular}

the production and re-production of each unit of the product in the factory, control and storage in the warehouse, the collection of the product from the customer, and the disassembly of the product in the disassembly center. Also, for all shipments between the supply chain components, the cost is calculated separately. The second part of the objective function, which includes variable costs and the cost of moving parts, is considered uncertain under limited scenarios. Given that decisions are made in two different instances and strategic decisions of the first stage affect the decisions of the second stage, the model is presented as a two-stage stochastic programming. The sum of the three mentioned parts (fixed costs, variable costs, 
Table 4. Binary decision variables of the problem.

\begin{tabular}{cc}
\hline Notation & \multicolumn{1}{c}{ Description } \\
$F p_{i}$ & $\begin{cases}1 & \text { if plant } i \text { is established } \\
0 & \text { o.w }\end{cases}$ \\
$F w_{j}$ & $\begin{cases}1 & \text { if warehouse } j \text { is established } \\
0 & \text { o.w }\end{cases}$ \\
$F d_{l}$ & $\begin{cases}1 & \text { if DC } l \text { is established } \\
0 & \text { o.w }\end{cases}$
\end{tabular}

and shipping costs) is the stochastic objective function of the problem.

$$
\begin{aligned}
\min z= & \sum_{i=1}^{I} c p_{i} F p_{i}+\sum_{j=1}^{J} c w_{j} F w_{j}+\sum_{l=1}^{L} c d_{l} F d_{l} \\
& +\sum_{s=1}^{S} \theta^{s}\left(\sum_{i=1}^{I} c^{\prime} p_{i} \sum_{j=1}^{J} \sum_{m=1}^{M} P W_{i, j, m}^{s}\right) \\
& +\sum_{s=1}^{S} \theta^{s}\left(\sum_{j=1}^{J} c^{\prime} h_{j} \sum_{k=1}^{K} \sum_{n=1}^{N} W C_{j, k, n}^{s}\right) \\
& +\sum_{s=1}^{S} \theta^{s}\left(\sum_{k=1}^{K} c^{\prime} c_{k} \sum_{j=1}^{J} \sum_{n=1}^{N} W C_{j, k, n}^{s}\right) \\
& +\sum_{s=1}^{S} \theta^{s}\left(\sum_{j=1}^{J} c^{\prime} d_{l} \sum_{k=1}^{K} \sum_{o=1}^{O} C I_{k, l, o}^{s}\right) \\
& +\sum_{s=1}^{S} \theta^{s}\left(\sum_{i=1}^{I} \theta_{j=1}^{J} \sum_{m=1}^{M} c^{\prime \prime} p_{i, j, m} P W_{i, j, m}^{s} c^{\prime} r_{i} \sum_{l=1}^{L} \sum_{p=1}^{P} I P_{k, l, p}^{s}\right)
\end{aligned}
$$

$$
\begin{aligned}
& +\sum_{s=1}^{S} \theta^{s}\left(\sum_{j=1}^{J} \sum_{k=1}^{K} \sum_{n=1}^{N} c^{\prime \prime} w_{j, k, n} W C_{j, k, n}^{s}\right) \\
& +\sum_{s=1}^{S} \theta^{s}\left(\sum_{k=1}^{K} \sum_{l=1}^{L} \sum_{o=1}^{O} c^{\prime \prime} c_{k, l, o} C I_{k, l, o}^{s}\right) \\
& +\sum_{s=1}^{S} \theta^{s}\left(\sum_{l=1}^{L} \sum_{i=1}^{I} \sum_{p=1}^{P} c^{\prime \prime} d_{l, i, p} I P_{l, i, p}^{s}\right) .
\end{aligned}
$$

$\mathrm{CO}_{2}$ emission released by the production and reproduction at the plants, storage and control in the warehouses, and disassembly in DCs is equal to $T E(1)$. $\mathrm{CO}_{2}$ released in various methods via transportation between the components is also equal to $T E(2)$. Relation (4) indicates that the total gas released by $T E(1)$ and $T E(2)$ must be less than or equal to the upper bound of emission capacity $\left(\right.$ cap $\left.^{s}\right)$.

$$
\begin{aligned}
T E(1)= & \sum_{i=1}^{I} e p_{i} \sum_{j=1}^{J} \sum_{m=1}^{M} P W_{i, j, m}^{s} \\
& +\sum_{j=1}^{J} e w_{j} \sum_{k=1}^{K} \sum_{n=1}^{N} W C_{j, k, n}^{s} \\
& +\sum_{l=1}^{L} e d_{l} \sum_{k=1}^{K} \sum_{o=1}^{O} C I_{k, l, o}^{s} \\
& +\sum_{i=1}^{I} e r_{i} \sum_{l=1}^{L} \sum_{p=1}^{P} I P_{l, i, p}^{s}, \\
T E(2)= & \sum_{m=1}^{M} e^{\prime \prime} p_{m} \sum_{i=1}^{I} \sum_{j=1}^{J} \gamma p_{i, j, m} s p_{i, j} P W_{i, j, m}^{s} \\
& +\sum_{n=1}^{N} e^{\prime \prime} w_{n} \sum_{i=1}^{I} \sum_{j=1}^{J} \gamma w_{j, k, n} s w_{j, k} W C_{j, k, n}^{s}
\end{aligned}
$$

Table 5. Continuous decision variables of the problem.

\begin{tabular}{cl}
\hline Notation & \multicolumn{1}{c}{ Description } \\
\hline$P W_{i, j, m}^{s}$ & $\begin{array}{l}\text { Amount of unit product shipped from plant } i \text { to warehouse } j \text { by the transportation } \\
\text { method } m \text { in scenario } s\end{array}$ \\
$W C_{j, k, n}^{s}$ & $\begin{array}{l}\text { Amount of unit product shipped from warehouse } j \text { to customer } k \text { by the transportation } \\
\text { method } n \text { in scenario } s\end{array}$ \\
$C I_{k, l, o}^{s}$ & $\begin{array}{l}\text { Amount of unit product to be disposed collected from customer } k \text { to DC } l \text { by the transportation } \\
\text { method } o \text { in scenario } s\end{array}$ \\
$I P_{l, i, p}^{s}$ & $\begin{array}{l}\text { Amount of unit product to be dismantled shipped from DC } l \text { to plant } i \text { by the transportation } \\
\text { method } p \text { in scenario } s\end{array}$ \\
\hline
\end{tabular}




$$
\begin{aligned}
& \sum_{o=1}^{O} e^{\prime \prime} c_{o} \sum_{k=1}^{K} \sum_{l=1}^{L} \gamma c_{k, l, o} s c_{k, l} C I_{k, l, o}^{s} \\
& +\sum_{p=1}^{P} e^{\prime \prime} d_{p} \sum_{j=1}^{J} \sum_{k=1}^{K} \gamma d_{l, i, p} s d_{l, i} I P_{l, i, p}^{s},
\end{aligned}
$$

$$
T E(1)+T E(2) \leq c a p^{s} \forall s \in S \text {. }
$$

Relations (5)-(8) are capacity constraints. Relation (5) indicates that the total amount of materials sent from a plant to various warehouses should be as large as the capacity of the plant. In Relation (6), the total of all materials from different plants to a warehouse should be as large as the capacity of the warehouse. Relation (7) represents the total products shipped from different customers to each DC. This value should not exceed the capacity of that disassembly center. Relation (8) also shows that the total of products shipped from each DC to plants should be as large as the reproduction capacity of that plant.

$$
\begin{aligned}
& \sum_{j=1}^{J} \sum_{m=1}^{M} P W_{i, j, m}^{s} \leq u p_{i} F p_{i} \forall i \in I, s \in S, \\
& \sum_{i=1}^{I} \sum_{m=1}^{M} P W_{i, j, m}^{s} \leq u w_{j} F w_{j} \forall j \in J, s \in S, \\
& \sum_{l=1}^{L} \sum_{o=1}^{O} C I_{k, l, o}^{s} \leq u d_{l} F d_{l} \forall l \in L, s \in S, \\
& \sum_{l=1}^{L} \sum_{p=1}^{P} I P_{l, i, p}^{s} \leq u r_{i} F p_{i} \forall i \in I, s \in S .
\end{aligned}
$$

Output flow from each warehouse must be less than or equal to the input flow. This is the case in Relation (9). This constraint is used for material flow balances.

$$
\sum_{i=1}^{I} \sum_{m=1}^{M} P W_{i, j, m}^{s} \geq \sum_{k=1}^{K} \sum_{n=1}^{N} W C_{j, k, n}^{s} \forall j \in J, s \in S .
$$

Relation (10) indicates that the sum of products coming from different warehouses to a customer should not be less than customer demand since shortage in our model is not allowed.

$$
\sum_{j=1}^{J} \sum_{n=1}^{N} W C_{j, k, n}^{s} \geq d_{k}^{s} \forall k \in K, s \in S
$$

Relation (11) states that products that are collected from each customer for different DCs should not be greater than the total customer demand that can be provided by the company. Each customer can return the defective product to DCs as much as the total demand.

$$
\sum_{l=1}^{L} \sum_{o=1}^{O} C I_{k, l, o}^{s} \leq d_{k}^{s} \forall k \in K, s \in S .
$$

Relations (12) and (13) force the model to establish a reverse flow in the supply chain. In Relation (12), the model is forced to send a minimum percentage of customer demand to the DCs. Relation (13) also forces the model to send a minimum percentage of return and output products to the factory for re-production.

$$
\begin{aligned}
& \sum_{l=1}^{L} \sum_{o=1}^{O} C I_{k, l, o}^{s} \leq \alpha \times d_{k}^{s} \forall k \in K, s \in S, \\
& \sum_{i=1}^{I} \sum_{p=1}^{P} I P_{l, i, p}^{s} \leq \alpha^{\prime} \times \sum_{k=1}^{K} C I_{k, l, o}^{s} \forall l \in L, s \in S .
\end{aligned}
$$

The presented model is an MILP. $F p_{i}, F w_{j}$, and $F d_{l}$ are binary variables for the construction of plants, warehouses, and DCs. $P W_{i, j, m}^{s}, W C_{j, k, n}^{s}, C I_{k, l, o}^{s}$, and $I P_{l, i, p}^{s}$ are continuous variables for setting up the flow between various components of the GSC.

$$
\begin{aligned}
& F p_{i}, F w_{j}, F d_{l} \in\{0,1\} \\
& P W_{i, j, m}^{s} \geq 0, W C_{j, k, n}^{s} \geq 0, C I_{k, l, o}^{s} \geq 0, I P_{l, i, p}^{s} \geq 0 .
\end{aligned}
$$

\section{The proposed solution method}

Since the proposed MILP model has high computational complexity, it seems necessary to provide an effective solution method that can achieve the optimal solution in a limited number of iterations. Benders algorithm is one of the exact decomposition methods first proposed in [37]. This algorithm is based on fixing the hard variables. The process of fixing hard variables is called relaxation. With the relaxation of these variables in the solution, the complexity of the problem can be greatly reduced. As Benders decomposition is known as a method that achieves converged quite slowly [38], we propose a novel solution method in order to accelerate the solution algorithm. The process of the proposed algorithm is shown in Figure 2. The details of the Benders reformulation of the MIP model, along with the proposed accelerator of the algorithm, are presented in what follows.

\subsection{Reformulation of the regular Benders decomposition method}

As mentioned, the prevalent Benders decomposition approach is the first one proposed to solve the model. 


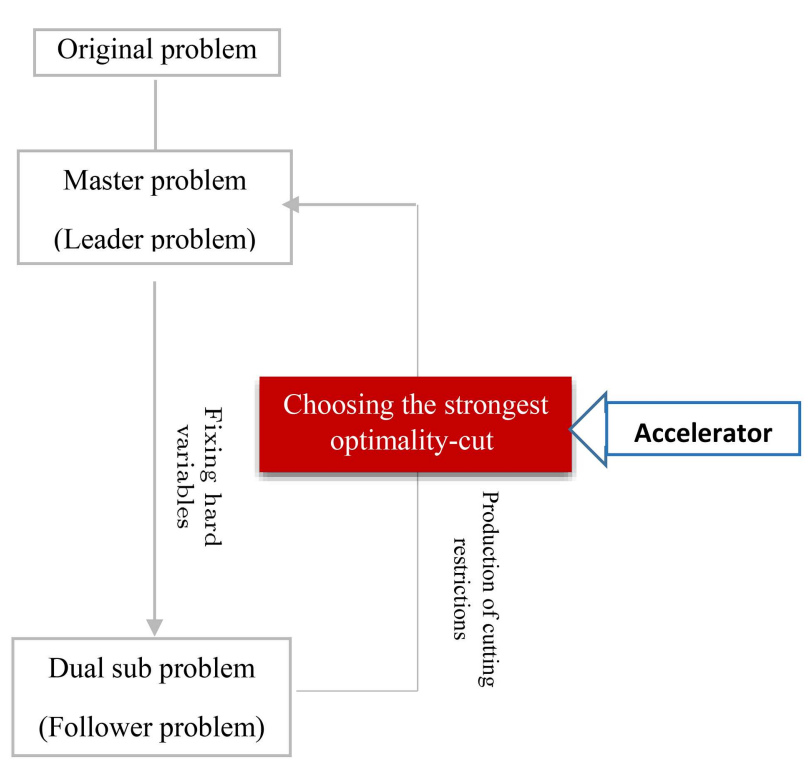

Figure 2. Steps followed in the proposed accelerated Benders algorithm to get the optimal solution.

The regular Benders decomposition method has been widely used in recent studies on the supply chain network design $[39,40]$. The general steps of a typical Benders algorithm to achieve the optimal solution through upper and lower bound convergence is as follows.

\subsubsection{Solving the Master Problem (MP)}

In this study, binary variables of constructing facilities were considered as hard variables because, in solving a problem, the procedure for dealing with integer variables varies with other variables. Also, the degree of complexity depends on the number of the discrete variables. After the hard variables are determined, MP model is written. MP is a model that only possesses hard variables. After solving, if our MP model has an infinite response, we select a feasible solution.

\subsubsection{Solving the Dual Sub-Problem (DSP)}

Sub-Problem (SP) is a model that contains all the variables of the problem except the hard variables. DSP is a dual SP. DSP model is solved by using the feasible solution to the MP problem. First, for each constraint of the SP model, a dual variable is determined. In this study, all constraints apply to the SP model. Dual variables of the problem for each constraint are $\beta^{s}, \delta_{i}^{s}, \varepsilon_{j}^{s}, \eta_{j}^{s}, \lambda_{k}^{s}, \mu_{k}^{s}, \xi_{l}^{s}, \tau_{k}^{s}, \chi_{l}^{s}$, and $\omega_{i}^{s}$, respectively. The form of the DSP model is as follow:

$$
\begin{aligned}
\max Z D S P & =-\sum_{s=1}^{S} \beta^{S} \cdot c a p^{s}-\sum_{i=1}^{I} \sum_{s=1}^{S} u p_{i} \cdot F p_{i} \cdot \delta_{i}^{s} \\
& -\sum_{j=1}^{J} \sum_{s=1}^{S} u w_{j} \cdot F w_{j} \cdot \varepsilon_{j}^{s}+\sum_{k=1}^{K} \sum_{s=1}^{S} d_{k}^{s} \cdot \lambda_{k}^{s}
\end{aligned}
$$

$$
\begin{aligned}
& -\sum_{k=1}^{K} \sum_{s=1}^{S} d_{k}^{s} \cdot \mu_{k}^{s}-\sum_{l=1}^{L} \sum_{s=1}^{S} u d_{l} \cdot F d_{l} \cdot \xi_{l}^{s} \\
& +\sum_{k=1}^{K} \sum_{s=1}^{S} \alpha \cdot d_{k}^{s} \cdot \tau_{k}^{s}-\sum_{i=1}^{I} \sum_{s=1}^{S} u r_{i} \cdot F p_{i} \cdot \omega_{i}^{s} \\
& \text { s.t.: } \\
& \left(-e p_{i}-e^{\prime \prime} p_{m} \cdot \gamma p_{i, j, m} . s p_{i, j}\right) \cdot \beta^{s}-\delta_{i}^{s}-\varepsilon_{j}^{s}+\eta_{j}^{s} \\
& \leq\left(c^{\prime} p_{i}+c^{\prime \prime} p_{i, j, m}\right) \cdot \theta^{s} \forall i, j, m, s, \\
& \left(-e w_{j}-e^{\prime \prime} w_{n} \cdot \gamma w_{j, k, n} \cdot s w_{j, k}\right) \cdot \beta^{s}-\eta_{j}^{s}+\lambda_{k}^{s} \\
& \leq\left(c^{\prime} h_{j}+c^{\prime \prime} w_{j, k, n}\right) \cdot \theta^{s} \forall j, k, n, s, \\
& \left(-e d_{l}-e^{\prime \prime} c_{o} \cdot \gamma c_{k, l, o} . s c_{k, l}\right) \cdot \beta^{s}-\mu_{k}^{s}-\xi_{l}^{s}+\tau_{k}^{s} \\
& \leq\left(c^{\prime} c_{k}+c^{\prime} d_{l}+c^{\prime \prime} c_{k, l, o}\right) \cdot \theta^{s} \forall k, l, o, s, \\
& \left(-e r_{i}-e^{\prime \prime} d_{p} \cdot \gamma d_{l, i, p} . s d_{l, i}\right) \cdot \beta^{s}+\chi_{l}^{s}-\omega_{i}^{s} \\
& \leq\left(c^{\prime} r_{i}+c^{\prime \prime} d_{l, i, p}\right) \cdot \theta^{s} \forall l, i, p, s, \\
& \beta^{s} \geq 0, \delta_{i}^{s} \geq 0, \varepsilon_{j}^{s} \geq 0, \eta_{j}^{s} \geq 0, \lambda_{k}^{s} \geq 0, \mu_{k}^{s} \geq 0, \\
& \xi_{l}^{s} \geq 0, \tau_{k}^{s} \geq 0, \chi_{l}^{s} \geq 0, \omega_{i}^{s} \geq 0 .
\end{aligned}
$$

\subsubsection{Calculating the lower bound}

In each iteration of the algorithm, for each corner point of the DSP problem, an optimality cut is added to the MP problem. Also, DSP model may have an infinite response due to the extreme directions. To solve this problem, feasibility cut is added to the MP. Considering these changes, the MP model in iterations of more than one is as follows:

$\min Z_{L}^{\prime}$,

s.t.:

$$
\begin{aligned}
Z_{L}^{\prime} \geq \sum_{i=1}^{I} c p_{i} \cdot F p_{i}+\sum_{j=1}^{J} c w_{j} \cdot F w_{j}+\sum_{l=1}^{L} c d_{l} \cdot F d_{l} \\
\quad-\sum_{s=1}^{S}\left(c a p^{s}\right) \cdot \beta^{s(w)}-\sum_{i=1}^{I} \sum_{s=1}^{S}\left(u p_{i} \cdot F p_{i}\right) \cdot \delta_{i}^{s(w)} \\
\quad-\sum_{j=1}^{J} \sum_{s=1}^{S}\left(u w_{j} \cdot F w_{i}\right) \cdot \varepsilon_{j}^{s(w)}+\sum_{k=1}^{K} \sum_{s=1}^{S}\left(d_{k}^{s}\right) \cdot \lambda_{k}^{s(w)} \\
\quad-\sum_{k=1}^{K} \sum_{s=1}^{S}\left(d_{k}^{s}\right) \cdot \mu_{k}^{s(w)}-\sum_{l=1}^{L} \sum_{s=1}^{S}\left(u d_{l} \cdot F d_{l}\right) \cdot \xi_{l}^{s(w)} \\
\quad+\sum_{k=1}^{K} \sum_{s=1}^{S}\left(\alpha \cdot d_{k}^{s}\right) \cdot \tau_{k}^{s(w)}-\sum_{i=1}^{I} \sum_{s=1}^{S}\left(u r_{i} \cdot F p_{i}\right) \\
\quad . \omega_{i}^{s(w)} \forall i, j, k, l, w=1, \ldots, W
\end{aligned}
$$




$$
\begin{aligned}
& -\sum_{s=1}^{S}\left(c a p^{s}\right) \cdot \beta^{s(r)}-\sum_{i=1}^{I} \sum_{s=1}^{S}\left(u p_{i} \cdot F p_{i}\right) \cdot \delta_{i}^{s(r)} \\
& -\sum_{j=1}^{J} \sum_{s=1}^{S}\left(u w_{j} \cdot F w_{i}\right) \cdot \varepsilon_{j}^{s(r)} \\
& +\sum_{k=1}^{K} \sum_{s=1}^{S}\left(d_{k}^{s}\right) \cdot \lambda_{k}^{s(r)}-\sum_{k=1}^{K} \sum_{s=1}^{S}\left(d_{k}^{s}\right) \cdot \mu_{k}^{s(r)} \\
& -\sum_{l=1}^{L} \sum_{s=1}^{S}\left(u d_{l} \cdot F d_{l}\right) \cdot \xi_{l}^{s(r)}+\sum_{k=1}^{K} \sum_{s=1}^{S}\left(\alpha \cdot d_{k}^{s}\right) \cdot \tau_{k}^{s(r)} \\
& -\sum_{i=1}^{I} \sum_{s=1}^{S}\left(u r_{i} \cdot F p_{i}\right) \cdot \omega_{i}^{s(r)} \leq 0 \\
& \forall i, j, k, l, r=1, \ldots, R, \\
& \left\{\beta^{s(w)}, \delta_{i}^{s(w)}, \varepsilon_{j}^{s(w)}, \eta_{j}^{s(w)}, \lambda_{k}^{s(w)}, \mu_{k}^{s(w)}, \xi_{l}^{s(w)}, \tau_{k}^{s(w)}\right. \\
& \left.\chi_{l}^{s(w)}, \omega_{i}^{s(w)}\right\} \in E_{\rho}, \\
& \left\{\beta^{s(r)}, \delta_{i}^{s(r)}, \varepsilon_{j}^{s(r)}, \eta_{j}^{s(r)}, \lambda_{k}^{s(r)}, \mu_{k}^{s(r)}, \xi_{l}^{s(r)}, \tau_{k}^{s(r)}\right. \\
& \left.\chi_{l}^{s(r)}, \omega_{i}^{s(r)}\right\} \in R_{u} .
\end{aligned}
$$

In this model, $E_{\rho}$ is the set of DSP corner points, $R_{u}$ the set of extreme directions, and $Z_{L}^{\prime}$ the lower bound.

\subsubsection{Check stop condition}

In each iteration, the upper bound $Z_{U}$ is computed as the sum of the objective functions of the MP and the DSP. Also, stop condition is defined as follows:

$$
\left|Z_{U}-Z_{L}\right| \leq \phi
$$

If the upper and lower bounds are lower than or equal to $\phi$, the algorithm stops and optimal solution is obtained. Otherwise, the new optimality cutting and feasibility cut should be added to the problem.

\subsection{Algorithm enhancement}

Although a study has used the regular Benders algorithm to solve the problem of the low-carbon supply chain network design [41], the accelerated Benders algorithm has not yet been proposed for the design of green closed-loop networks. Our study presents a novel accelerated Benders algorithm based on the Paretooptimal cut. This sub-section proposes the details of the accelerator modeling method.

If the DSP has multiple optimal solutions, the number of optimality-cuts is innumerable, because the problem solving space is continuous and linear. Therefore, in order to choose the strongest optimal cut, the following model is to be solved after solving the DSP. $\left\{F p_{i}^{o}, F w_{j}^{o}, F d_{l}^{o}\right\}$ inner points of the convex series are the solutions to the DSP problem (core points).

$$
\begin{aligned}
\max \text { Zpareto } & =-\sum_{s=1}^{S} \beta^{s} \cdot c a p^{s}-\sum_{i=1}^{I} \sum_{s=1}^{S} u p_{i} \cdot F p_{i} \cdot \delta_{i}^{s} \\
& -\sum_{j=1}^{J} \sum_{s=1}^{S} u w_{j} \cdot F w_{j} \cdot \varepsilon_{j}^{s}+\sum_{k=1}^{K} \sum_{s=1}^{S} d_{k}^{s} \cdot \lambda_{k}^{s} \\
& -\sum_{k=1}^{K} \sum_{s=1}^{S} d_{k}^{s} \cdot \mu_{k}^{s}-\sum_{l=1}^{L} \sum_{s=1}^{S} u d_{l} \cdot F d_{l} \cdot \xi_{l}^{s} \\
& +\sum_{k=1}^{K} \sum_{s=1}^{S} \alpha \cdot d_{k}^{s} \cdot \tau_{k}^{s}-\sum_{i=1}^{I} \sum_{s=1}^{S} u r_{i} \cdot F p_{i} \cdot \omega_{i}^{s} \\
& +\sum_{i=1}^{I} c p_{i} \cdot F p_{i}^{o}+\sum_{j=1}^{J} c w_{j} \cdot F w_{j}^{o}+\sum_{l=1}^{L} c d_{l} \cdot F d_{l}^{o},
\end{aligned}
$$

s.t.:

$$
\begin{aligned}
&-\sum_{s=1}^{S} \beta^{s} . c a p^{s}-\sum_{i=1}^{I} \sum_{s=1}^{S} u p_{i} \cdot F p_{i} \cdot \delta_{i}^{s} \\
&-\sum_{j=1}^{J} \sum_{s=1}^{S} u w_{j} \cdot F w_{j} \cdot \varepsilon_{j}^{s}+\sum_{k=1}^{K} \sum_{s=1}^{S} d_{k}^{s} \cdot \lambda_{k}^{s} \\
&-\sum_{k=1}^{K} \sum_{s=1}^{S} d_{k}^{s} \cdot \mu_{k}^{s}-\sum_{l=1}^{L} \sum_{s=1}^{S} u d_{l} \cdot F d_{l} \cdot \xi_{l}^{s} \\
&+\sum_{k=1}^{K} \sum_{s=1}^{S} \alpha \cdot d_{k}^{s} \cdot \tau_{k}^{s}-\sum_{i=1}^{I} \sum_{s=1}^{S} u r_{i} \cdot F p_{i} \cdot \omega_{i}^{s} \\
&=D S P-\sum_{i=1}^{I} c p_{i} \cdot F p_{i}-\sum_{j=1}^{J} c w_{j} \cdot F w_{j} \\
&-\sum_{l=1}^{L} c d_{l} \cdot F d_{l} \text { Zpareto } \in D S P \\
&\left\{F p_{i}^{o}, F w_{j}^{o}, F d_{l}^{o}\right\} \in \text { core points. }
\end{aligned}
$$

In addition to these constraints, DSP constraints also exist this model. The solution to this model ensures that the strongest optimality cut is selected. 


\section{Experimental examples and sensitive analysis}

In this section, the mathematical model and the accelerated Benders algorithm are subject to numerical testing and sensitivity analysis. Different data sources were considered to extract the parameter values [4245]. For example, two sources were used to determine the amount of $\mathrm{CO}_{2}$ released [44,45]. To do various experiments in this section, the model includes three plants, three warehouses, eight customers, and three DCs. Three possible scenarios (optimistic, realistic, and pessimistic) for each non-deterministic parameter are also considered. Table 6 demonstrates information about the uncertain parameters of the problem. The amount of emission capacity in pessimistic terms is equal to $4000000 \mathrm{~kg}$, in optimistic terms equal to $1000000 \mathrm{~kg}$, and in realistic conditions equal to $2000000 \mathrm{~kg}$. These values vary with the weather and environmental conditions. Considering different circumstances, three different values for each customer demand are also determined.

The upper bound of emission capacity and customer demand are independent. Given the occurrence probability of independent events, the total number of probable scenarios is obtained by multiplying the number of $c a p^{s}$ scenarios by the number of $d_{k}^{s}$ scenarios. The occurrence probability of each scenario in Table 6 is also obtained by multiplying the probability of each parameter. Table 7 provides a guide to the acronyms used for names of scenarios in Table 6 .

General and accelerated Benders algorithms are used to solve the mathematical model. Figure 3 shows the number of iterations for general Benders algorithm and Figure 4 gives the number of iterations for the accelerated Benders algorithm to equalize the upper and lower bounds. Figure 5 also shows the convergence trends of the lower and upper bounds of the proposed accelerated Benders decomposition algorithm. These figures represent the optimal performance of the algorithm.
Table 7. Names of scenarios.

\begin{tabular}{|c|c|}
\hline Scenario name & Description \\
\hline ocpd & Optimistic $c a p^{s}$, pessimistic $d_{k}^{s}$ \\
\hline rcpd & Realistic $c a p^{s}$, pessimistic $d_{k}^{s}$ \\
\hline pcpd & Pessimistic $c a p^{s}$, pessimistic $d_{k}^{s}$ \\
\hline ocrd & Optimistic $c a p^{s}$, realistic $d_{k}^{s}$ \\
\hline rerd & Realistic cap $^{s}$, realistic $d_{k}^{s}$ \\
\hline pcrd & Pessimistic $c a p^{s}$, realistic $d_{k}^{s}$ \\
\hline ocod & Optimistic $c a p^{s}$, optimistic $d_{k}^{s}$ \\
\hline $\operatorname{rcod}$ & Realistic $c a p^{s}$, optimistic $d_{k}^{s}$ \\
\hline pcod & Pessimistic $c a p^{s}$, optimistic $d_{k}^{s}$ \\
\hline
\end{tabular}

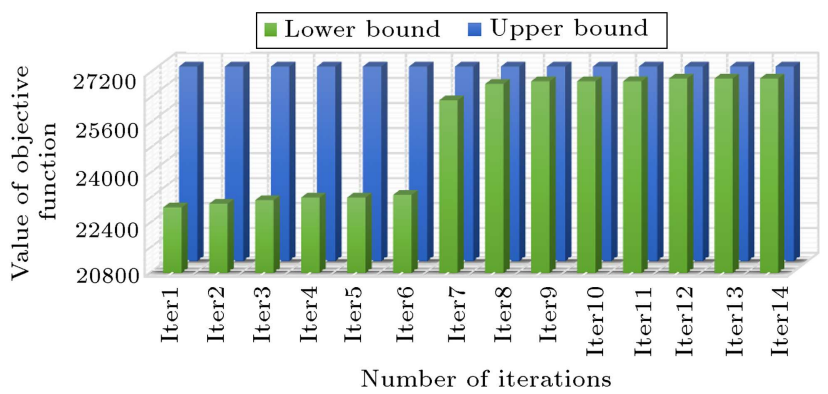

Figure 3. Iterations of the regular Benders algorithm.

To investigate the effect of change in the nondeterministic parameters on the value of the objective function, various analyses of the model were performed. Table 8 illustrates the effect of the value of $c a p^{s}$ changing on the value of the objective function. Figure 6 shows the sensitivity of the objective function value to different greenhouse gas emission factors. According to this figure, by reducing the upper bound of emission capacity, the total cost increases. In the model, the lowest upper bound of greenhouse gas emission capacity is $177000 \mathrm{~kg}$.

The other uncertain parameter examined is $d_{k}^{s}$. Table 9 states the effect of the value of $d_{k}^{s}$ changing on the value of objective function. Figure 7 demonstrates

Table 6. Values of non-deterministic parameters in different scenarios, occurrence probability of each parameter, and scenario probabilities.

\begin{tabular}{|c|c|c|c|c|c|c|c|c|c|c|c|c|c|}
\hline \multirow{3}{*}{$\begin{array}{l}\text { Number of } \\
\text { scenarios }\end{array}$} & \multicolumn{3}{|c|}{$\operatorname{cap}^{s}$} & \multicolumn{10}{|c|}{$d_{k}^{s}$} \\
\hline & \multirow{2}{*}{$\begin{array}{l}\text { Name of } \\
\text { scenario }\end{array}$} & \multirow{2}{*}{$\begin{array}{c}\text { Probability of } \\
\text { occurrence }\end{array}$} & \multirow{2}{*}{$\begin{array}{c}\text { Value of } \\
\text { parameter }(\mathrm{kg})\end{array}$} & \multirow{2}{*}{$\begin{array}{c}\text { Probability of } \\
\text { occurrence }\end{array}$} & \multicolumn{8}{|c|}{ Value of parameter (ton) } & \multirow{2}{*}{$\begin{array}{c}\text { Probability of } \\
\text { scenario }\end{array}$} \\
\hline & & & & & C1 & $\mathrm{C} 2$ & C3 & $\mathrm{C} 4$ & C5 & C6 & C7 & $\mathrm{C8}$ & \\
\hline $\mathrm{S} 1$ & ocpd & 0.2 & 4000000 & 0.25 & 30 & 29 & 18 & 29 & 18 & 28 & 18 & 17 & 0.05 \\
\hline $\mathrm{S} 2$ & repd & 0.6 & 2000000 & 0.25 & 30 & 29 & 18 & 29 & 18 & 28 & 18 & 17 & 0.15 \\
\hline S3 & pcpd & 0.2 & 1000000 & 0.25 & 30 & 29 & 18 & 29 & 18 & 28 & 18 & 17 & 0.05 \\
\hline $\mathrm{S} 4$ & ocrd & 0.2 & 4000000 & 0.5 & 20 & 28 & 15 & 23 & 16 & 20 & 17 & 16 & 0.1 \\
\hline S5 & rerd & 0.6 & 2000000 & 0.5 & 20 & 28 & 15 & 23 & 16 & 20 & 17 & 16 & 0.3 \\
\hline S6 & pcrd & 0.2 & 1000000 & 0.5 & 20 & 28 & 15 & 23 & 16 & 20 & 17 & 16 & 0.1 \\
\hline S7 & ocod & 0.2 & 4000000 & 0.25 & 11 & 27 & 12 & 17 & 14 & 12 & 15 & 14 & 0.05 \\
\hline S8 & $\operatorname{rcod}$ & 0.6 & 2000000 & 0.25 & 11 & 27 & 12 & 17 & 14 & 12 & 15 & 14 & 0.15 \\
\hline S9 & pcod & 0.2 & 1000000 & 0.25 & 11 & 27 & 12 & 17 & 14 & 12 & 15 & 14 & 0.05 \\
\hline
\end{tabular}


Table 8. The effect of the value of $c a p^{s}$ on the objective function.

\begin{tabular}{|c|c|c|c|c|c|c|c|}
\hline & \multicolumn{7}{|c|}{ No. } \\
\hline & 1 & 2 & 3 & 4 & 5 & 6 & 7 \\
\hline $\begin{array}{l}\text { (Optimistic, } \\
\text { realistic, } \\
\text { pessimistic) } \\
\text { (Ton) }\end{array}$ & $(300,270,240)$ & $(280,250,220)$ & $(260,230,200)$ & $(240,210,190)$ & $(220,200,185)$ & $(200,190,180)$ & $(190,185,178)$ \\
\hline $\begin{array}{c}\text { Objective } \\
\text { value }\end{array}$ & 25710.758448 & 25770.979144 & 25921.996456 & 26082.203164 & 26300.065259 & 26627.697268 & 26775.126793 \\
\hline
\end{tabular}

Table 9. The effect of the value of $d_{k}^{s}$ on the objective function.

\begin{tabular}{lcccccccc}
\hline & \multicolumn{7}{c}{ No. } \\
\cline { 2 - 8 } & 1 & 2 & 3 & 4 & 5 & 6 & 7 & 8 \\
\hline $\begin{array}{l}\text { Unit demand } \\
\text { increased for } \\
\text { all costumers }\end{array}$ & 0 & 1 & 2 & 3 & 4 & 5 & 6 & 7 \\
$\begin{array}{l}\text { Objective } \\
\text { value }\end{array}$ & 17250.32 & 18602.34 & 19958.36 & 21334.88 & 22739.4 & 24151.17 & 25575.19 & 27026.71 \\
\hline
\end{tabular}

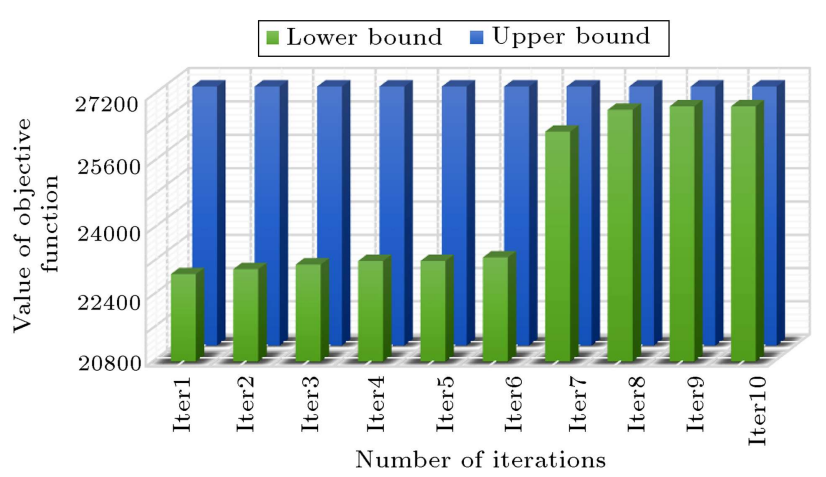

Figure 4. Iterations of the proposed accelerated Benders algorithm.

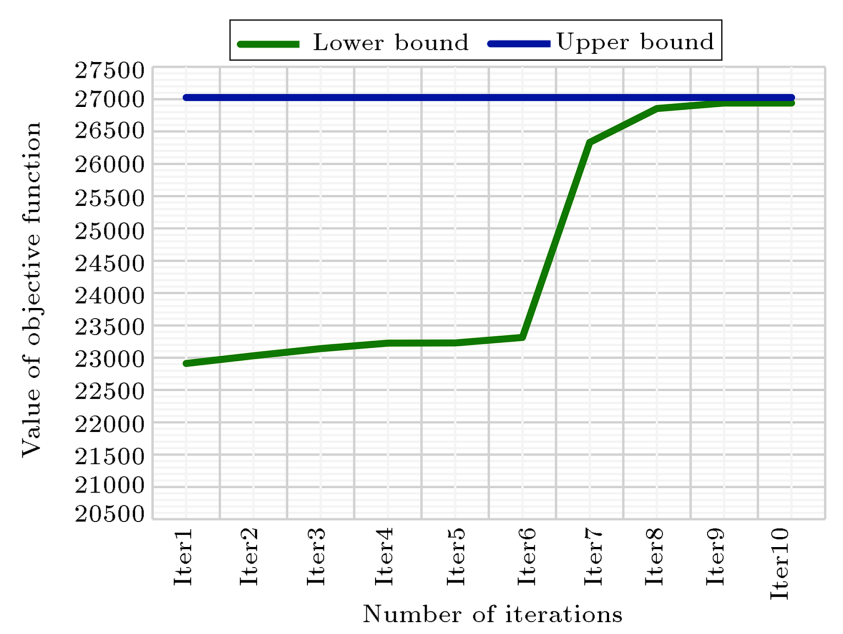

Figure 5. Convergence progression of the proposed accelerated Benders algorithm.

the effect of this parameter on the values of the objective function. According to this figure, total cost increases with increase in demand for all customers.

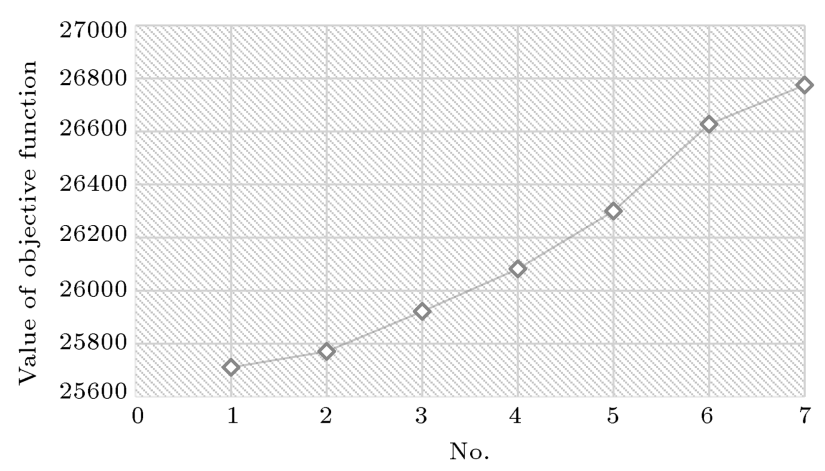

Figure 6. Increase in the value of the objective function by decreasing cap ${ }^{s}$.

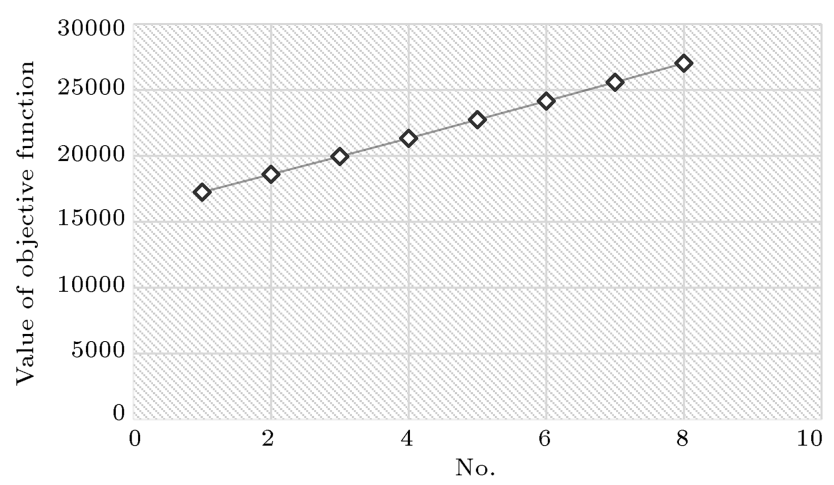

Figure 7. Increase in the value of the objective function by increasing $d_{k}^{s}$.

The probability of scenarios is another factor affecting the total cost of the model. Among all possible scenarios, "ocod" is the most optimistic scenario that might happen. According to Figure 8, with increase in the probability of this scenario, the total cost is reduced. The best solution that could be given to this mathematical model is when the probability of this 


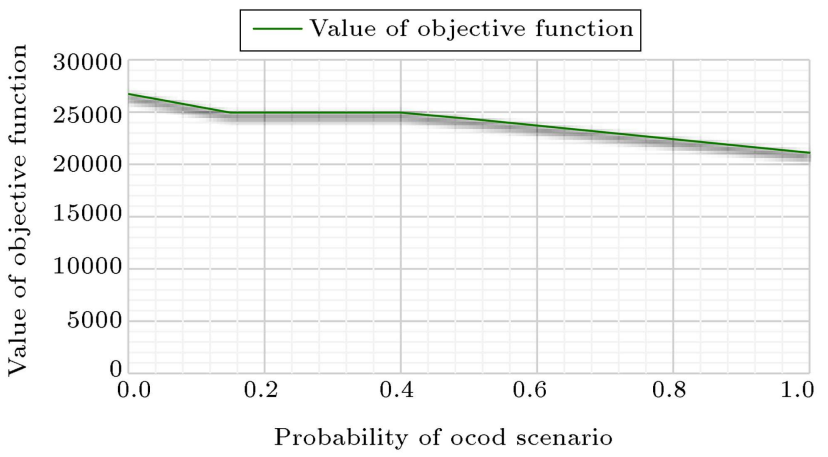

Figure 8. The effect of the probability of the "ocod" scenario on the objective function.

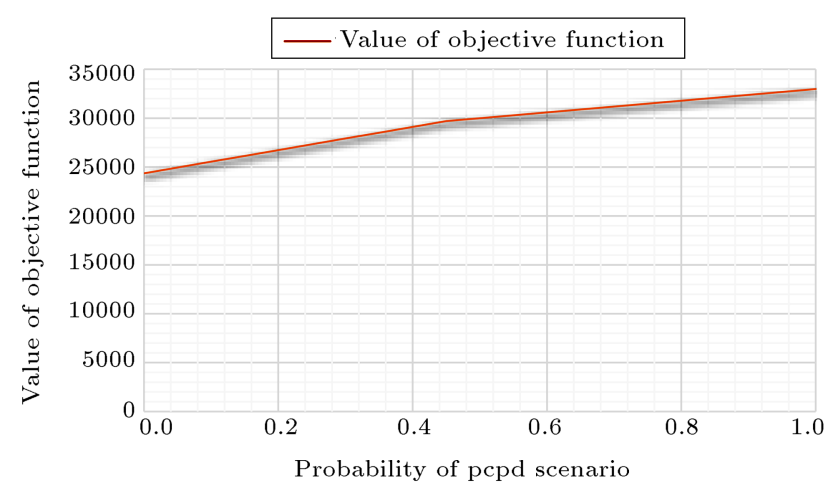

Figure 9. The effect of the probability of the "pcpd" scenario on the objective function.

scenario equals 1 and the model is to be solved in the deterministic mode.

Another scenario being examined is the "pcpd" scenario. This scenario is likely to be the most pessimistic scenario. Figure 9 illustrates that with the increasing probability of the "pcpd" scenario, the total cost increases. The worst solution that could be given to this mathematical model is when the probability of this scenario equals 1 and the model is solved in definite mode.

\section{Conclusion and future research}

This paper presents a two-stage stochastic programming model for designing a green closed-loop supply chain network. In this model, various factors of uncertainty were controlled and customer demand and the upper bound of greenhouse gas emissions were assumed uncertain. The performance of the proposed algorithm was compared with the regular Benders algorithm. The number of iterations for accelerated Benders algorithm was lower than the regular Benders algorithm. In the end, to analyze the sensitivity of the objective function, various factors influencing the total cost were examined. Based on these factors, increasing probability of the most optimistic scenario and reducing probability of the most pessimistic scenario would improve the overall performance of the supply chain and maximize productivity. Also, increasing the amount of emission capacity and reducing customer demand would reduce the overall cost of the design.

The proposed model has great potential for development. Given that in the mathematical model, the time value of money is not considered, we can use the time value coefficients for more realistic calculations of the costs. The model can be developed in the form of multi-stage stochastic programming approach. To solve the proposed model, more advanced algorithms can be used. Furthermore, to solve this model in large scale, it is possible to increase the convergence speed of the upper and lower bounds by sub-problem division into smaller sub-problems and producing several optimal cuttings in each iteration.

\section{References}

1. WCED. Our Common Future. World Commission on Environment and Development. Oxford University Press, UK (1987).

2. Nurjanni, K.P., Carvalho, M.S., and Costa, L. "Green supply chain design: A mathematical modeling approach based on a multi-objective optimization model", International Journal of Production Economics, 183, pp. 421-432 (2017).

3. Chopra, S. and Meindl, P., Supply Chain Management. Strategy, Planning \& Operation, In: Boersch, C., and Elschen, R., Eds., Das Summa Summarum des Management. Gabler, pp. 265-275 (2007).

4. Yang, P., Wee, H., Chung, S., et al. "Sequential and global optimization for a closed-loop deteriorating inventory supply chain", Mathematical and Computer Modelling, 52(12), pp. 161-176 (2010).

5. Che, Z.-H., Chiang, T.-A., Tu, C., et al. "A supplier selection model for product design changes", International Journal Engineering Business Management, 8(1), pp. 20-30 (2010).

6. Moncayo-Martínez, L.A. and Zhang, D.Z. "Multiobjective ant colony optimisation: a meta-heuristic approach to supply chain design", International Journal of Production Economics, 131(1), pp. 407-420 (2011).

7. Jamshidi, R., Ghomi, S.F., and Karimi, B. "Multiobjective green supply chain optimization with a new hybrid memetic algorithm using the Taguchi method", Scientia Iranica, 19(6), pp. 1876-1886 (2012).

8. Tognetti, A., Grosse-Ruyken, P.T., and Wagner, S.M. "Green supply chain network optimization and the trade-off between environmental and economic objectives", Int. J. Production Economics, 170, pp. 385-392 (2015).

9. Shaw, K., Irfan, M., Shankar, R., et al. "Low carbon chance constrained supply chain network design problem: A benders decomposition based approach", Computers \& Industrial Engineering, 98, pp. 483-497 (2016). 
10. Varsei, M. and Polyakovskiy S. "Sustainable supply chain network design: A case of the wine industry in Australia", Omega-International Journal of Management Science, 66, pp. 236-47 (2017).

11. Devikaa, K., Jafarian, A., and Nourbakhsh, V. "Designing a sustainable closed-loop supply chain network based on triple bottom line approach", European Journal of Operational Research, 235(3), pp. 594-615 (2014).

12. Mohammed, A. and Wang, Q. "The fuzzy multiobjective distribution planner for a green meat supply chain", Int. J. Production Economics, 184, pp. 47-58 (2017).

13. Soleimani, H. and Kannan, G. "A hybrid particle swarm optimization and genetic algorithm for closedloop supply chain network design in large-scale networks", Applied Mathematical Modelling, 39(14), pp. 3990-4012 (2015).

14. Imran, M., Kang, C.W., and Ramzan M.B. "Medicine supply chain model for an integrated healthcare system with uncertain product complaints", Journal of Manufacturing Systems, 46, pp. 13-28 (2018).

15. Mirakhorli, A. "Multi-objective optimization of reverse logistics network with fuzzy demand and return- product using an interactive fuzzy goal programming approach", 40th International Conference on Computers and Industrial Engineering (CIE), pp. 1-6 (2010).

16. Paksoy, T., Pehlivan, N.Y., and Ozceylan, E. "Fuzzy multi-objective optimization of a green supply chain network with risk management that includes environmental hazards", Human and Ecological Risk Assessment: An International Journal, 18(5), pp. 1120-1151 (2012).

17. Paksoy, T., Pehlivan, N.Y., and Ozceylan, E. “A new tradeoff model for fuzzy supply chain network design and optimization", Human and Ecological Risk Assessment: An International Journal, 19(2), pp. 492-514 (2013).

18. Yilmaz, B.S. and Selim, H. "Sustainable design of renewable energy supply chains integrated with district heating systems: a fuzzy optimization approach", Journal of Cleaner Production, 133, pp. 863-885 (2016).

19. Paydar, M.M., Babaveisi, V., and Safaei, A.S. "An engine oil closed-loop supply chain design considering collection risk", Computers \& Chemical Engineering, 104, pp. 38-55 (2017).

20. Amin, S.H., Zhang, G., and Akhtar, P. "Effects of uncertainty on a tire closed-loop supply chain network", Expert Systems with Applications, 73, pp. 8291 (2017).

21. Santoso, T., Ahmed, S., Goetschalckx, M., et al. "A stochastic programming approach for supply chain network design under uncertainty", European Journal of Operational Research, 167(1), pp. 96-115 (2005).

22. Pan, F. and Nagi, R. "Robust supply chain design under uncertain demand in agile manufacturing",
Computers \& Operations Research, 37(4), pp. 668-683 (2010).

23. Zeballos, L.J., M_endez, C.A., Barbosa-Povoa, A.P., et al. "Multi-period design and planning of closed-loop supply chains with uncertain supply and demand", Computers \& Chemical Engineering, 66, pp. 151-164 (2014).

24. Khatami, M., Mahootchi, M., and Farahani, R.Z. "Benders' decomposition for concurrent redesign of forward and closed-loop supply chain network with demand and return uncertainties", Transportation Research, Part E: Logistic and Transportation Review, 79, pp. 1-21 (2015).

25. Keyvanshokooh, E., Ryan, S.M., and Kabir, E. "Hybrid robust and stochastic optimization for closed loop supply chain network design using accelerated benders decomposition", European Journal of Operational Research, 249(1), pp. 76-92 (2016).

26. Rezaee, A., Dehghanian, F., Fahimnia, B., et al. "Green supply chain network design with stochastic demand and carbon price", Annals of Operations Research, 250(2), pp. 463-485 (2017).

27. Pasandideh, S.H.R., Niaki, S.T.A., and Asadi, K. "Optimizing a bi-objective multiproduct multi-period three echelon supply chain network with warehouse reliability", Expert Systems with Applications, 42(5), pp. 2615-2623 (2015).

28. Banasik, A., Kanellopoulos, A., Claassen, G.D.H., et al. "Closing loops in agricultural supply chains using multi-objective optimization: A case study of an industrial mushroom supply chain", International Journal of Production Economics, 183, pp. 409-420 (2017)

29. Heidari-Fathian, H. and Pasandideh, S.H.R. "Greenblood supply chain network design: Robust optimization, bounded objective function \& Lagrangian relaxation", Computer \& Industrial Engineering, 122, pp. 95-105 (2018).

30. Ramudhin, A., Chaabane, A., and Paquet, M. "Carbon market sensitive sustainable supply chain network design", International Journal of Management Science and Engineering Management, 5(1), pp. 30-38 (2010).

31. Kamali, A., Ghomi, S.M., and Jolai, F. "A multi objective quantity discount and joint optimization model for coordination of a single-buyer multi-vendor supply chain", Computers \& Mathematics with Applications, 62(8), pp. 3251-3269 (2011).

32. Pati, R., Jans, R., and Tyagi, R.K. "Green logistics network design: a critical review", Production \& Operations Management, 25, pp. 1-10 (2013).

33. Ozkır, V. and Başlıgil, H. "Multi objective optimization of closed loop supply chains in uncertain environment", Journal of Cleaner Production, 41, pp. 114-125 (2013).

34. Ruimin, M.A., Lifei, Y.A.O., Maozhu, J.I.N., et al. "Robust environmental closed-loop supply chain design under uncertainty", Chaos, Solitons \& Fractals, 89, pp. 195-202 (2016). 
35. Jerbia, R., Boujelben, M.K., Sehli, M.A., et al "Stochastic closed-loop supply chain network design problem with multiple recovery options", Computers \& Industrial Engineering, 118, pp. 23-32 (2018).

36. Mohammadi, A.S., Alemtabriz, A., Pishvaee, M.S., et al. "A multi-stage stochastic programming model for sustainable closed-loop supply chain network design with financial decisions: A case study of plastic production and recycling supply chain", Scientia Iranica, 27(1), pp. 377-395 (2019).

37. Benders, J.F. "Partitioning procedures for solving mixed-variables programming problems", Numerische Mathematik, 4(1), pp. 238-252 (1962).

38. Geoffrion, A.M. and Graves, G.W. "Multi-commodity distribution system design by Benders decomposition", Management Science, 20(5), pp. 822-844 (1974).

39. Naderi, B., Govindan, K., and Soleimani, H. "A Benders decomposition approach for a real case supply chain network design with capacity acquisition and transporter planning: wheat distribution network", Annals of Operation Research, 291, pp. 685-705 (2020).

40. Hendalianpour, A., Fakhrabadi, M., Sangari, M., et al. "A combined benders decomposition and lagrangian relaxation algorithm for optimizing a multi-product, multi-level omni-channel distribution system", Scientia Iranica, Trans. E, Industrial Eng., 29(1), pp. 355371 (2022). DOI: $10.24200 /$ sci.2020.53644.3349

41. Shaw, K., Irfan, M., Shankar, R., et al. "Low carbon chance constrained supply chain network design problem: A benders decomposition based approach", Computers \& Industrial Engineering, 98, pp. 483-497 (2016).

42. Tsiakis, P., Shah, N., and Pantelides, C.C. "Design of multi-echelon supply chain networks under demand uncertainty", Industrial Engineering and Chemical Research, 40(16), pp. 3585-3604 (2001).
43. Google Maps, April 2019. Find local businesses, view maps and get driving directions. < https://maps. google.com $>$.

44. Heidelberg Cement Group, April 2019. Castlecementsustainability2007.

<http:// www.heidelbergcement.com/NR/rdonlyres/ DF6E404C-8B50-4A1D-8818-671155C78236/0/

Castle_cement_sustainability_review.pdf $>$.

45. UKWA, April 2019. Save energy, energy efficient warehouse operation (2010).

$<$ http://www.ukwa.org.uk/_files/23-carbon-trust23.pdfu>.

\section{Biographies}

Amin Reza Kalantari Khalil Abad accomplished his BSc and MSc in Industrial Engineering at Meybod University, Yazd, Iran, and Kharazmi University, Tehran, Iran, respectively. His main research focuses on the design of green and sustainable supply chain networks, logistics and transportation, and optimization methods.

Seyed Hamid Reza Pasandideh received his BSc, $\mathrm{MSc}$, and $\mathrm{PhD}$ in Industrial Engineering from Sharif University of Technology, Tehran, Iran. Also, he has done a Postdoctoral program at the University of Nebraska-Lincoln, Lincoln, USA. He is currently an Associate Professor in the Department of Industrial Engineering at Kharazmi University. His research interest is concentrated on inventory control and optimization of nonlinear, multi-objective models; logistics; and transportation problems. $\mathrm{He}$ is an editor of the International Journal of Supply and Operations Management. 